\title{
(t)
}

\section{FEMINISMOS NO BRASIL CONTEMPORÂNEO: APONTAMENTOS CRÍTICOS E DESAFIOS ORGANIZATIVOS}

\author{
FEMINISMS IN CONTEMPORARY BRAZIL: CRITICAL \\ NOTES AND ORGANIZATIONAL CHALLENGES
}

\section{Telma Gurgel'}

\section{RESUMO}

Analisar as transformações no feminismo brasileiro, nos últimos trinta anos, é o objetivo central deste artigo que resultou de um estudo teórico-crítico acerca de três categorias que concebem o feminismo como movimento social na dinâmica da luta de classes, quais sejam: a noção de autonomia, a questão do financiamento e a construção da representatividade coletiva, compreendidas como uma unidade dialética do processo de organização do sujeito feminista no contexto de neoliberalismo. Com o estudo, conclui-se que o feminismo brasileiro tem inúmeros desafios políticos no campo da democracia interna, da representatividade política e da agenda de mobilização, no sentido de se constituir como um sujeito coletivo total ao reconhecer e fortalecer as diversas formas de organizações das mulheres em seu confronto com o patriarcado, racismo e capitalismo.

Palavras-chave: Feminismo. Autonomia. Coletivo total.

\section{ABSTRACT}

Analyze the changes in Brazilian feminism, in the last thirty years, is the central aim of the article that resulted from a theoretical and critical

\footnotetext{
1 Assistente Social. Mestre em Ciências Sociais pela Universidade Federal do Rio Grande do Norte (2000) e doutorado em Sociologia pela Universidade Federal da Paraíba (2004). Professora adjunto IV da Universidade do Estado do Rio Grande do Norte. Tem experiência na área de Serviço Social e da Sociologia, com ênfase nos estudos das relações sociais de gênero e do feminismo. E-mail: telmagurgeluern@gmail.com.
} 


\section{temporalis}

study of three categories that circulate feminism as a social movement in the dynamics of class struggle, which are: the notion of autonomy, the question of financing and the construction of collective representation, understood as a dialectical unity of feminist subject process organization in the context of neoliberalism. With this study we conclude that Brazilian feminism has numerous political challenges in the field of internal democracy, of political representation and of mobilization Agenda to be constituted as a total collective subject when recognizes and strengthens the various forms of women's organizations in their confrontation with patriarchy, racism and capitalism.

Keywords: Feminism. Autonomy. Total collective.

Submetido em 26/03/2014

Aceito em 22/06/2014

\section{INTRODUÇÃO}

O debate em torno do caráter emancipacionista no feminismo se inicia com o seu surgimento como sujeito político, no século XVIII. Desde então, a luta das mulheres tem acompanhado o movimento geral da classe trabalhadora por outra sociabilidade, fundada nos princípios de solidariedade, igualdade, liberdade e emancipação humana.

Apesar de sua participação concreta em vários momentos da história social, as mulheres e suas lutas nem sempre foram aceitas pelas organizações dos trabalhadores, seja nos sindicatos, seja nos partidos políticos. Remontam daí vários registros dos debates teóricos entre Clara Zétkin e Lenin sobre o caráter estratégico do movimento de mulheres para a luta socialista².

A experiência do socialismo real evidenciou essa problemática na medida em que as transformações na base produtiva não alteraram as relações de poder e de desigualdade entre homens e mulheres. Os escritos de Kollontai (1982) acerca da emergência de uma nova moral como base para a destruição do patriarcado, considerado fundamento ideológico do capitalismo, são exemplos que podemos destacar na difícil incorporação das demandas de liberdade e autonomia das mulheres, pela esquerda mundial socialista.

2 Sobre isso, temos como sugestão a leitura de GONZÁLEZ, Ana Isabel Álvarez. As origens e a comemoração do dia internacional das mulheres: Sof-expressão popular. São Paulo, 2010; e GURGEL, Telma. O feminismo como sujeito coletivo total: a mediação da diversidade. Cadernos de Crítica Feminista, Recife, ano V, n. 4, p. 30-48, 2011. 
No geral, os conflitos se davam em torno da noção de autonomia, da questão da auto-organização, da composição social do feminismo e da relação entre a luta geral pelo socialismo e as lutas específicas das mulheres. No sentido amplo, as organizações de esquerda tiveram grandes dificuldades em reconhecer o caráter estratégico da luta das mulheres, bem como a questão da auto-organização no interior dos partidos e demais coletivos.

Ao mesmo tempo que o feminismo enfrentava esses pontos de conflitos com a esquerda, era visto com desconfiança pelo projeto político das classes burguesas, já que se confrontava diretamente com as expressões do patriarcado, ao denunciar, segundo Camurça (2007), o controle da sexualidade, a divisão sexual de trabalho, a violência contra a mulher e a desigualdade no acesso à política.

Para além dessas questões, o feminismo ainda se defronta internamente com um conjunto de tensionamentos em torno das diferentes experiências de opressão vivenciadas pelas mulheres e das concepções de programas, estratégias, alianças e desafios organizativos daí decorrentes.

Neste artigo, refletimos sobre a noção de autonomia, a questão do financiamento e a construção da representatividade coletiva, apreendidas como uma unidade dialética, mediante um estudo teórico-crítico com base em publicações acerca do feminismo como movimento social. Nessa perspectiva, abordamos essas três categorias e seus rebatimentos no processo de organização do sujeito coletivo feminista em sua relação com as diversas institucionalidades, destacando dentre elas o Estado, em contexto de neoliberalismo ${ }^{3}$.

3 O neoliberalismo é em primeiro lugar uma teoria das práticas políticoeconômicas que propõe que o bem-estar humano é condicionado a liberdades e capacidades empreendedoras individuais no âmbito de uma estrutura institucional caracterizada por sólidos direitos a propriedade privada, livre mercado e livre comércio. O papel do Estado é criar e preservar uma estrutura institucional apropriada a essas práticas. O Estado, entre outras coisas, deve também estabelecer as estruturas e funções militares, de defesa, da polícia, e legais, requeridas para garantir os direitos de propriedades individuais e o funcionamento apropriado dos mercados (HARVEY, 2008, p. 12). 


\section{temporalis}

Consideramos que os estudos a respeito da ação política dos movimentos sociais e suas contradições internas se tornam necessários para o esforço coletivo de compreensão dos desafios de nosso tempo histórico, como afirma Mészáros (2007). O autor também reafirma a produção de conhecimento no âmbito do serviço social articulada aos interesses de transformação social, no caso específico da superação das desigualdades entre os sexos.

Assim, iniciamos o texto com o debate acerca da autonomia como elemento demarcatório no processo de organização interna do movimento. Em seguida, abordamos a questão do financiamento e da relação do feminismo com as institucionalidades, destacando entre elas o Estado. Finalizando o debate sobre as categorias, apresentamos a questão da representatividade coletiva do movimento e os dilemas da composição social deste.

\section{AUTONOMIA E PRÁXIS FEMINISTA}

A autonomia tem sido um tema de debate permanente no processo de construção do feminismo como sujeito coletivo a partir de pelo menos quatro aspectos: 1) com relação aos espaços institucionais do Estado, sindicatos e partidos políticos; 2) na defesa da auto-organização; 3) na prerrogativa da representação direta; e 4) na expressão pública de radicalidade, contestação e ousadia.

Até final dos anos de 1980, os debates sobre autonomia se centravam na crítica à dupla militância de feministas com atuação no movimento e em partidos políticos, principalmente, no campo da esquerda e das organizações clandestinas. De um lado, temia-se que houvesse um processo de partidarização das lutas e interesses do movimento, descaracterizando a crítica a organizações políticas tradicionais, uma das bases teórico-políticas do feminismo.

Por outro lado, havia receio de que o contato das feministas com as mulheres populares ${ }^{4}$, a partir da ação dos partidos, provocasse um rebaixamento programático do feminismo, uma vez

4 A composição social do feminismo à época, ressaltadas as diferenças entre os países, era predominantemente de mulheres brancas, classe média, com acesso à educação formal, e militante de esquerda. 
que, no geral, as reivindicações desse setor social se encerravam na conquista das políticas públicas e na garantia de mecanismos de participação política das mulheres. Nessa direção, o feminismo esvaziaria sua força política de questionamento do tripé patriarcardo, capitalismo e racismo como dimensões de uma mesma totalidade social. A crítica se centralizava, muitas vezes, nas práticas assistencialistas desenvolvidas por algumas organizações feministas no Brasil, nessa década5.

A autonomia, nos anos de 1980, também era reivindicada como princípio feminista, no sentido do direito da auto-organização no interior do próprio movimento. Tal demanda era explicitada, segundo Fischer (2005), pelas feministas lésbicas e negras, que defendiam reuniões específicas para deliberação exclusivas desse segmento, sem a presença das mulheres heterossexuais ou brancas.

Para além dessa demanda inicial, podemos reafirmar que o reconhecimento da diversidade das mulheres no interior do feminismo é central para a sua construção como sujeito coletivo e tem sido ponto de pauta nos encontros feministas latino-americanos desde essa época, conforme podemos destacar:

[...] O feminismo como movimento social [...] vai se construindo em diversidade de formas e suas manifestações são múltiplas e existe pouca ou nenhuma articulação entre elas. Essa heterogeneidade, que reflete necessidades diferentes e diversos níveis de consciência, exige encontrar demandas conjuntas para avançar na construção de um movimento amplo e autônomo (EFLAC, 1990, p. 18-21).

Importa destacar que em nosso país, a partir desse período, com o retorno de algumas mulheres brasileiras que haviam sido exiladas no período da ditadura (PINTO, 2003), os grupos feministas se ampliam em diversos espaços. Ao mesmo tempo, o movimento conquista políticas públicas como o Programa de Atenção

5 No final dos anos de 1980, em pleno processo de transição da ditadura militar para o regime civil, certos grupos feministas priorizaram a estratégia de se aproximar das mulheres populares, a partir de uma articulação com programas governamentais. Sobre esse tema, consultar Gurgel (2005) e Falquet (2011), indicadas nas referências deste texto. 


\section{temporalis}

Integral à Saúde da Mulher (PAISM), as primeiras delegacias de defesa das mulheres, a instauração dos Conselhos dos Direitos das Mulheres, em todas as esferas de governo. Mesmo que consideremos que eram ações bastante incipientes e com enormes dificuldades de se impor como prioridade no debate orçamentário, essas iniciativas marcaram a visibilidade do feminismo e ampliaram a sua densidade política na conjuntura nacional.

Ocorre que, em finais dos anos de 1990, a significação atribuída à autonomia pelo feminismo se deslocou da questão da especificidade da autodeterminação do movimento de mulheres, em relação aos partidos políticos, ganhando o terreno de outra institucionalidade mediante a consolidação das Organizações Não Governamentais feministas (ONGs).

Como reordenamento da relação entre movimentos sociais e Estado na América Latina, pós-ditaduras militares, a ampliação das ONGs feminista foi contemporânea às crises organizativas da classe trabalhadora diante da ofensiva neoliberal, no Brasil, durante os anos de 1990. Nesse mesmo período, presenciamos uma tímida reação da classe trabalhadora ao processo de reestruturação produtiva e de desemprego estrutural, claramente percebida quando nos referimos ao processo de mobilização e participação política em torno da garantia das conquistas históricas da classe trabalhadora, no contexto da América Latina e no Brasil, como afirma Behring (2003).

O fenômeno das ONGs está, portanto, relacionado a um contexto mais amplo de estruturação do capitalismo e cumpre um papel estratégico, sob o ponto de vista da transferência de responsabilidade de programas e políticas que deveriam ser executadas pelo Estado, para o chamado terceiro setor (MONTAÑO; DURIGUETO, 2011).

No campo do feminismo, podemos destacar pelo menos duas críticas à "onguização" que podem esclarecer os conflitos que repercutem na construção da autodeterminação e auto-organização das mulheres e do movimento feminista enquanto sujeito coletivo. 
A primeira diz respeito à transformação da identidade institucional, que trouxe como consequência imediata uma redução política e quantitativa da base social do movimento de mulheres que constituía a anterioridade política da ONG.

A segunda crítica se centra na estrutura administrativa que transferiu as decisões político-institucionais para as equipes de profissionais das ONGs, que na maioria dos casos se apresentam como ativistas e confundem o papel de assessoria com o de representatividade.

O problemático desse quadro é a contradição entre o princípio da autonomia no processo de autodeterminação, com o crescimento individual e coletivo, das mulheres no exercício da política e a centralidade de poder, nas estruturas das ONGs.

Ainda nos cabe destacar que essa transformação contribuiu para a profissionalização de militantes que se distanciam cada vez mais de uma atuação na base social, ao assumirem um fazer política que reproduz as esferas de hierarquização e centralidade decisórias, fenômenos cuja negação é um dos fundamentos teórico-políticos do feminismo como sujeito coletivo.

\section{A QUESTÃO DO FINANCIAMENTO}

Além das mudanças explicitadas no item anterior, ao desenvolver projetos com recursos de organismos de cooperação internacional, o fenômeno das ONGs evidenciou a questão do financiamento do movimento. Para Falquet (2003), algumas dessas agências agiam como intermediárias de fundos advindos de organismos financeiros que eram os principais responsáveis pelo crescimento da pobreza e desigualdades no continente, como o Fundo Monetário Internacional (FMI), o Banco Interamericano de Desenvolvimento (BID) e o Banco Mundial (BM).

A contradição entre os interesses de autodeterminação das mulheres e as relações institucionais construídas mediante esses financiamentos é focalizada na maioria dos estudos sobre o movimento na América Latina. Alvarez (2000) e Castro (1997, 2000), em suas reflexões, abordam a historicidade desse processo como um dos indicadores de uma provável perda de autonomia do 


\section{temporalis}

movimento para a realização de ações com maior combatividade e radicalidade ${ }^{6}$.

A crítica se centra, portanto, no ajustamento discursivo de algumas ONGs feministas que passam a determinar suas linhas de ações e estratégias a partir das demandas das agências de cooperação internacional, ao se submeterem a um mercado de projeto, estabelecido pelos insteresses hegemônicos desses organismos de cooperação?.

Para além dessa crítica, o feminismo também enfrenta a reflexão sobre o poder político de algumas ONGs que, mediante o acesso aos financiamentos, passam a controlar as informações estratégicas e contribuem para a seletividade de projetos a partir da referência à práxis política dos grupos, conforme assinala Fischer (2005, p. 65): “[...] o financiamento também produziu concorrência entre as feministas [...] e tem como uma de suas consequências a negação de recursos a correntes do feminismo que não compactuam e criticam as negociações com o governo e os organismos multilaterais".

Nesse sentido, a aproximação das ONGs com esse tipo de financiamento, além de contribuir para a quebra do princípio de sororidade $^{8}$ que fundamenta o feminismo, igualmente provocou o desenvolvimento de práticas políticas de invisibilidade da crítica.

No contexto atual das lutas de classes no Brasil, esse posicionamento contribui para a redução dos espaços públicos democráticos, ao colaborar com o esvaziamento do poder de articulação e de adesão popular aos movimentos sociais e ao estabelecer parâmetros de credibilidade política referenciados na relação de

6 Apesar de se reconhecer a existência de práticas diferenciadas entre as ONGs em relação a essa política de adequação discursiva.

7 Fischer (2005) apresenta uma distinção entre as agências, destacando que existem fundos de apoio que são oriundos do processo de mobilização e captação de recursos por meio de doações realizadas por grupos feministas dos países, numa clara perspectiva de solidariedade, respeito às demandas locais e de confiança entre as mulheres, contribuindo, assim, com a disseminação do feminismo como projeto político de liberdade.

8 Palavra de origem latina, que significa pacto entre as mulheres que se consideram irmãs, a irmandade entre mulheres. 
parceria, mesmo que pontual, com o Estado e, em algumas circunstâncias, com empresas e agentes financeiros.

Destacamos que, além dos financiamentos internacionais9, o contexto dos anos 1990 inaugura um período de maior acesso dos coletivos feministas, por meio das ONGs, aos fundos públicos nacionais, o que ocorre inclusive como resposta às orientações da cooperação internacional, que preconizava uma contrapartida das instituições, mediante aproximação com o Estado.

No Brasil, em particular, a partir do primeiro governo do Luiz Inácio Lula da Silva (2003-2006), verifica-se um crescimento da presença das feministas nos organismos governamentais, bem como o aumento do número de projetos desenvolvidos por ONGs feministas com apoio de fundos públicos ${ }^{10}$. Tal constatação nos leva a duas observações, de início.

Primeiramente, podemos constatar o envolvimento de lideranças feministas em governos com forte tendência à submissão à ordem capitalista mundial, como o brasileiro" ${ }^{11}$. Tal fato confunde e muitas vezes provoca cisões na base social do movimento que se construiu por meio da crítica aos valores patriarcais, capitalistas e em defesa da emancipação humana.

Em realidade, a maior repercussão dessa práxis se dá no enfraquecimento das perspectivas de aliança com setores com maior independência política do status quo no campo do feminismo ou do movimento social mais amplo.

Por outro lado, esse envolvimento manipulatório e financeiro, segundo Cisne (2013), além de favorecer o processo de implantação das medidas de ajustes impostas pelo receituário neoliberal de minimização e focalização das políticas, sem maiores

9 Cisne (2013) considera que atualmente houve um acentuado esvaziamento da presença dessas agências em nível da América Latina e do Brasil, em particular.

10 Os números de projetos e seus valores podem ser visualizados no portal: $<w w w . p o r t a l d a t r a n s p a r e n c i a . g o v . b r>$.

11 Indicamos a leitura de FATTORELLI, Maria Lúcia. Dívida brasileira e o paradoxo da desigualdade. São Leopoldo, 2013. Disponível em: <http://www.ihu.unisinos. br/entrevistas/525951-entrevista-especial-com-maria-lucia-fattorelli>. Acesso em: 21 mar. 2014. Além de ARTICULAÇÃO DE MULHERES BRASILEIRAS. Políticas públicas para a igualdade: balanço de 2003 a 2010 e desafios do presente. AMB: CFEMEA, Brasília, 2011. 


\section{temporalis}

resistências das mulheres, garante o barateamento do processo de reprodução social com a efetiva substituição do Estado pelas ONGs, na execução das políticas.

Por fim, não podemos deixar de comentar o nível de dependência financeira e exigências burocráticas que esses convênios governamentais geram para as ONGs, que passam a ser instituições cada vez mais profissionalizadas e com um corpo técnico captado muito mais pelas especialidades profissionais do que mesmo pela consciência feminista militante, debatida em Cisne (2013).

Como percebemos, a temática do financiamento das ONGs nos leva a refletir sobre a questão do Estado, tema que é recorrente na história do feminismo e que retorna com uma força impressionante, em contexto de transformismo ${ }^{12}$, na medida em que, como movimento social ou ONG, as ações desenvolvidas pelo feminismo têm, em grande parte, como ponto de interseção a interlocução direta com o Estado.

Tal condição política exige desse sujeito a compreensão de como essas demandas se entrelaçam com a economia política capitalista bem como do papel do Estado nessa relação, situado como elemento perpassado pelas lutas de classes.

Esse desafio demonstra a necessidade de o movimento se debruçar sobre o problema do Estado e desenvolver uma perspectiva analítico-política que realize o movimento dialético de conhecimento e transformação do poder exercido por este nos diversos campos da vida social.

Alvarez (2000, p. 14) propõe um debate em torno da "tradução política-cultural por parte do Estado”, ou seja, da capacidade que o Estado tem de ressignificar discursos. A compreeensão desse mecanismo ideológico do Estado e de sua relação com a autonomia do movimento feminista se evidencia na formulação

12 Consideramos que a categoria do transformismo, calcada por Gramsci como o processo histórico de adesão de indivíduos ou grupos de esquerda radical inteiros a projetos políticos que perpetuam escalas de dominação, é essencial para a compreensão do processo de transformação programática e de estratégia do ciclo de governos do Partido dos Trabalhadores, em nível central, até os dias atuais, conforme nos situa Cisne (2013). 
apresentada por Mandel (1985, p. 333-334) sobre as principais funções do Estado no capitalismo tardio:

1-criar as condições gerais de produção que não po-
dem ser asseguradas pelas atividades privadas dos
membros dominantes;
2-reprimir qualquer ameaça das classes dominadas
ou de facções particulares das classes dominantes,
ao modo de produção corrente através do exército,
da polícia, do sistema judiciário e penitenciário;
3-integrar as classes dominadas, garantir que a ideo-
logia da sociedade continue sendo a da classe domi-
nante e, em consequência, que as classes explora-
das aceitem sua própria exploração, sem o exercício
direto da repressão contra elas.

Essa teorização apresentada por Mandel expõe a tese do desenvolvimento "pluricausal" para o capitalismo, em períodos organizados em "ondas", que podem ser longas de tonalidade expansionista ou de estagnação, de acordo com a produtividade do trabalho e a repartição de renda entre capitalistas e trabalhadores.

Frente aos períodos de crises e de aumento dos riscos nos custos do processo de produção capitalista, o sistema, na figura do Estado, implementa políticas "anticíclicas" que promovem o processo de integração social dos setores à margem do mercado, fundamento da continuidade do status quo, do capitalismo.

Por outro lado, ao mesmo tempo que os governos neoliberais estabelecem políticas de financiamento que visam amenizar os impactos de seus ajustes estruturais, definem, desde a década de 1990, as ONGs como interlocutores privilegiados para as suas ações.

Dessa forma se estabelece um processo de hierarquização na definição de agendas políticas e encaminhamentos, no qual encontramos, de um lado, as ONGs, apoiadas e legitimadas pelos aparatos governamentais e de financiamento, de outro, os movimentos sociais, num processo acentuado de esvaziamento de sua legitimidade e poder de pressão. 


\section{temporalis}

A construção de espaços públicos que "criem denominadores comuns aos diversos setores que lutam quotidianamente contra a desigualdade e a exclusão em diversas frentes" (SILVEIRA, 1999, p. 02) é uma tarefa política urgente, diante da gradativa substituição dos movimentos sociais pela estrutura das ONGs, o que desafia o movimento feminista, em particular, a criar novas formas organizativas que ampliem o seu alcance político em bases sociais mais populares.

Essa conjuntura nos desperta para as ideias de Wainwright (2000, p. 122) sobre a relação do feminismo com o Estado, que deve apontar para duas direções: na primeira, o movimento deve "[...] propor uma alternativa à ditadura do mercado global [...] e afirmar que existem estratégias de transformação do Estado, dos meios de controlar o mercado e de reconstruir os serviços públicos". Além disso, o feminismo deve dar legitimidade ao Estado e deixar clara a necessidade de um Estado e de uma esfera cívica democrática, criando mecanismos de democracia direta e representação democrática.

Por fim, queremos abordar a questão democrática sugerida pela referida autora, mediante uma rápida apresentação de como se situa o debate da representatividade do movimento, outro pilar na atualidade dos desafios para o feminismo no Brasil.

\section{A CONSTRUÇÃO DA REPRESENTATIVIDADE}

A articulação entre o projeto comum e a representatividade coletiva é um grande desafio para movimentos sociais com composição heterogênea, como o feminismo, que conta em seu interior com sujeitos com diversas experiências de opressões, a saber: mulheres negras, lésbicas, bissexuais, jovens, indígenas, imigrantes, entre outras.

A noção de representatividade se problematiza a partir do sentido de totalidade que lhe é característico, pois indica, primeiramente, um processo de construção de identidade e de representação do ausente. Nesse sentido, a representatividade tem a prerrogativa de ser extensão do sujeito, com o problema concentrado nas questões relativas à outorga da representação e às deliberações no exercício desse poder. 
Na busca de elementos que podem nos subsidiar nessa reflexão, destacamos a força política do feminismo, em sua centralidade na denúncia e enfrentamento do patriarcado e suas dimensões de raça e classe: “[...]. O sistema patriarcal ataca as famílias populares rompendo a referência que tinham [...]. O principal efeito que tem o sistema patriarcal na mulher [...] é a falta de autoestima que se potencializa pela falta de liberdade para ser mulher" (EFLAC, 1990, p. 23).

Assim, a unidade na crítica ao patriarcado, como um sistema de dominação dos homens sobre as mulheres (DELPHY, 2000), possibilitou uma reflexão do poder na democratização da vida pública, não apenas no enfoque das conquistas normativas, do acesso das mulheres a mecanismos de representatividade política, ao trabalho e à educação, mas, sobremaneira, ao construir uma realidade social e uma cultura que reproduzam sistemas hierarquizantes da existência humana, como ocorreu com a condição de subordinação das mulheres.

Ao identificar o sistema patriarcal como o seu inimigo histórico (DELPHY, 2000), o feminismo definiu suas estratégias, tendo como base a superação dessa práxis de dominação. Assim sendo, como afirma Falquet (2011), a unidade relativa do feminismo em torno desse projeto emancipatório e a experiência de educação popular, impulsionadas pelas organizações de mulheres, são, sem dúvida, elementos que demarcam a memória social do feminismo, funcionando como catalizadores dos debates atuais em torno da representatividade do movimento, situado no contexto do neoliberalismo.

Contraditoriamente, o processo de "onguização" e de cooptação de lideranças feministas, por diversos governos, contribuiu para que o feminismo reproduzisse a força ideológica desse sistema, ao desenvolver novos centros de poder de decisão, a partir das ONGs e dos espaços nos conselhos, conferências e de negociação direta com o governo.

Isso ocorre porque a estruturação dos grupos em ONGs e a formalidade em suas parcerias assumem, como modelo organizativo jurídico e político, as referências adotadas pelo sistema 


\section{temporalis}

patriarcal de pensamento. Nesse sentido, o relatório do VIII Encontro Feminista Latino-Americano e do Caribe explicita:

Não somos somente nós, somos muitas mulheres que o têm denunciado: existe uma "onguização" do movimento. "Onguização" que tem pretendido estrangular-nos nos limites da legalidade. Construindo uma legitimidade jurídica e institucional que produz todas as hierarquias sociais, frente a elas, as autônomas temos construído uma legitimidade social histórica. A legitimidade social e histórica é uma legitimidade desde a prática social, desde as ruas e as zonas de sensibilidade de prazer e de dor de nossa sociedade e povos (EFLAC, 1990, p. 55).

A decorrência mais imediata dessa substituição de representatividade foi sobre a autonomia política das mulheres, com a mudança de cenário da luta social das ruas e pressão popular para a arena do monitoramento de políticas da perspectiva de empoderamento das mulheres no marco do capitalismo, da negociação nos gabinetes de governos e parlamentos. Isso ocorreu em detrimento da radicalidade e liberdade da crítica, que são próprias aos movimentos sociais em sua ação de pressão e enfrentamento com o sistema dominante, via demanda ao Estado.

Assim, a consolidação dessa nova representatividade do movimento aprofunda um conjunto de conflitualidades internas, que são geradas pela ausência de estruturas democráticas, de debates e de decisões que possibilitem "a quebra das hierarquias estabelecidas pelo status quo", como afirma Rosa Luxemburg (apud TRAGTEMBERG, 1991, p. 44).

Refletir sobre as evidências desse processo repercute como uma das tarefas para o feminismo contemporâneo, pois se trata de solucionar o impasse gerado entre a utopia libertária de seu projeto e a adequação necessária a uma prática de institucionalização.

A nosso ver, o dilema estratégico se centra muito mais na construção do feminismo como sujeito coletivo do que mesmo sobre a sua relação com outras institucionalidades, dentre elas o Estado ${ }^{13}$.

13 Que deve ser considerada diferentemente da sua institucionalização na 


\section{O FEMINISMO COMO UM COLETIVO TOTAL: O DESAFIO DA DIVERSIDADE}

O debate em torno do sujeito coletivo é uma das questões centrais que são postas para o feminismo na atualidade. Sua abordagem implica atualizações conceituais e, ao mesmo tempo, uma análise crítica de sua política no campo dos movimentos sociais.

Evidenciamos, com isso, o desafio da teoria feminista em superar os elementos que limitam sua perspectiva crítica do real e seu potencial de auto-organização das mulheres como força criadora de uma nova ordem. Nesse sentido, o feminismo tem como tarefa o desafio de constituir novos padrões de poder e de configurações de práxis.

No conjunto dos questionamentos em torno do papel e desafio do feminismo como movimento de contrapoder, o debate sobre estratégia assume, sem dúvida, uma importante centralidade e exige do movimento uma reflexão crítica de sua teoria e práxis social.

Para Castro (1997, p. 10), o feminismo deve reafirmar-se como "[...] um movimento social que se originou da ousadia libertária, contra cânones, reivindicando a materialização no imediato de utopias, o investimento em desidentificações - identificações".

Um passo importante nessa direção é não perder sua autonomia em função do tecnicismo corrente na realidade das políticas sociais, em especial as dirigidas às mulheres. Essas observações acerca do processo de "despolitização" e "tecnicismo" dos termos engendrados pelo feminismo podem ser aprofundadas com a discussão trazida por Mandel sobre a "mistificação da ideologia do racionalismo tecnológico", que

[...] proclama a capacidade que tem a ordem social vigente de eliminar gradualmente todas as possibilidades de crise, encontrar uma solução "técnica" para todas as suas contradições, [...] elevando-a a um mecanismo [...] independente de todos os

presença em movimentos mistos, já que para o feminismo o desafio é que as propostas construídas pelos movimentos sociais incluam questões relativas às mulheres como demandas sociais amplas e coletivas, além da garantia de autoorganização no interior desses espaços. 


\section{temporolis}

objetivos e decisões humanas, que age independentemente da estrutura e da dominação de classe [...] como uma lei natural (MANDEL, 1985, p. 351-353).

Esse racionalismo tecnológico nos programas destinados às mulheres tem ênfase no desenvolvimento de políticas pontuais e na despolitização dos atores e atrizes sociais com intervenção no contexto.

Assim, encontramos na contemporaneidade brasileira diversos grupos que, mesmo com um discurso de resistência às condições de opressão e subordinação vividas pelas mulheres, desenvolvem em sua práxis feminista um pragmatismo que é próprio do racionalismo técnico na gestão política das necessidades sociais, pelo Estado, no capitalismo tardio.

O desafio é desenvolver simultaneamente a crítica ao Estado e ao capitalismo, sem perder de vista as demais questões que constroem a identidade compartilhada das mulheres, seja na reivindicação de direitos sociais, seja no processo de oposição à estrutura patriarcalizada da sociedade.

Nesse panorama, a estratégia global do feminismo de enfrentamento ao patriarcado e aos sistemas que lhe dão sustentação deve reconhecer a heterogeneidade em sua formação, decorrente das diferentes experiências de opressão das mulheres, enquanto corpo individualizado e sujeito social. Essa perspectiva confere ao feminismo um duplo processo de construção como sujeito coletivo: o reconhecimento da diversidade e a construção de uma unidade diversa identitária.

Esse reconhecimento confere ao feminismo um movimento dialético que conforma uma unidade para sua construção como sujeito político: o reconhecimento da diversidade e a construção de uma unidade diversa que exprime "a aceitação das experiências particulares dentro da identidade coletiva" (GURGEL, 2011, p. 43), constituindo-se, assim, como um coletivo total.

Compreendemos que a categoria de coletivo total permite uma leitura das diversas singularidades no feminismo, sem hierarquização, pois, ao dar o ultimato do total, exige a descoberta das totalidades parciais. Ao mesmo tempo, reivindicar o total nos 
distancia dos riscos da fragmentação e/ou isolamento nas especificidades. Trata-se, portanto, do reconhecimento das particularidades no todo da diversidade que compõe um sujeito múltiplo.

O reconhecimento do sujeito múltiplo, como afirma Lauretis (1994), implica a estruturação de espaços permanentes de construção de política que aglutine os diversos sujeitos feministas, que, por sua vez, devem ser constantemente repensados e reatualizados em sua utopia e experiência.

Pensamos numa estrutura de horizontalidade como representação ontológica desse coletivo total, capaz de desenvolver mecanismos de participação direta e representativa em suas instâncias de decisões, construindo políticas que realizem a maior potencialidade do indivíduo: a sua condição de sujeito.

O feminismo como coletivo total proporciona, portanto, a inclusão horizontalizada das demandas específicas que compõem o sujeito "mulheres", ao assumir como princípio fundador as diversidades das mulheres.

Pensamos que, além de ser uma saída para o problema estratégico do sujeito feminista no Brasil, essa caracterização pode fundamentar as análises do movimento sobre sua autonomia, financiamento e representatividade, questões cruciais no processo de autodeterminação que a luta feminista exige, no contexto atual das lutas de classes no Brasil.

\section{REFERÊNCIAS}

ALVAREZ, Sônia. Em que Estado está o feminismo latino-americano: uma leitura crítica das políticas públicas com "perspectiva de gênero". In: FARIA, Nalu; SILVEIRA, Maria Lúcia; NOBRE, Míriam (Org.). Gênero nas políticas públicas: impasses e perspectivas para a ação feminista. São Paulo: SOF. 2000. p. 9-25. (Cadernos Sempreviva).

ARTICULAÇÃO DE MULHERES BRASILEIRAS. Políticas públicas para a igualdade: balanço de 2003 a 2010 e desafios do presente. Brasília: AMB; CFEMEA, 2011. 
BEHRING, Elaine Rossetti. O Brasil em Contrarreforma: destruturação do Estado e perda de direitos. São Paulo: Cortez, 2003.

CAMURÇA, Sílvia. "Nós Mulheres" e nossa experiência comum. Cadernos de Crítica Feminista, Recife, n. 0, p. 12-25, 2007.

CASTRO, Mary Garcia. Marxismo, feminismos e feminismo marxista: mais que um gênero em tempos neoliberais. Crítica Marxista, São Paulo, n. 11, p. 98-108, 2000.

. Feminismos e feminismos, reflexões à esquerda. Presença de Mulher, São Paulo, n. 29, p. 03-09, 1997.

CISNE, Mirla. Feminismo, luta de classes e consciência militante feminista no Brasil. 2013. Tese (Doutorado em Serviço Social) Programa de Pós-Graduação em Serviço Social, Universidade do Estado do Rio de Janeiro, Rio de Janeiro, 2013.

DELPHY, Christine. PATRIARCAT (THÉORIES DU). In: HIRATA, Helena et al. (Org.). Dictionnaire critique du féminisme. PUF: Paris. 2000. p. 141-146.

EFLAC. Relatório. V Encontro Feminista Latino-americano e do Caribe- V EFLAC. São Bernardo, Argentina, 1990.

. Relatório. VIII Encontro Feminista Latino-americano e do Caribe- VIII EFLAC. Santo Domingos, República Dominicana, 2000.

FALQUET, Jules. Le Mouvemement féministe em Amérique Latine et aux Caraïbes: défis et espoir face à la mondialisations néolibérale. Paris, 2011. Disponível em: <julesfalquet.worpress. com/>. Acesso em: 20 out. 2012.

. Femmes, féminisme et "développemente": une analyse critique des politiques des institutions internationales. Regards de femmes sur la globalisation: approches critiques. BISILLIAT, Jeanne (Org.). Paris: Karthala, 2003. p. 75-113.

FISCHER, Amalia. Los caminos complejos de la Autonomia. Nouvelles Questions Féministes: feminismos disidentes en 
América Latina e el Caribe. México: Ediciones fem-e-libros, 2005. v. 24, n. 2, p. 54-76.

GURGEL, Telma. A liberdade é lilás: a trajetória dos coletivos feministas em Mossoró (RN): Mossoró: Fundação Vingt-Un Rosado, 2005. (Coleção Mossoroense, Série C, v. 1447).

GURGEL, Telma. O feminismo como sujeito coletivo total: a mediação da diversidade. In: Cadernos de crítica feminista, Recife, ano V, n. 4, p. 30-47, 2011.

HARVEY, David. O neoliberalismo: histórias e implicações. São Paulo: Loyola, 2008.

KOLLONTAI, Alexandra. A nova mulher e a moral sexual. São Paulo: Global, 1982.

LAURETIS, Tereza. A tecnologia do gênero. In: HOLANDA, Heloísa Buarque (Org.). Tendências e impasses: o feminismo como crítica da cultura. Rio de Janeiro: Rocco, 1994. p. 206-243.

MANDEL, Ernest. O Capitalismo Tardio. Os Economistas. Apresentação de Paul Singer. Tradução de Carlos Eduardo Silveira Matos, Régis de Castro Andrade e Dinahr de Abreu Azevedo. 2. ed. São Paulo: Nova Cultural, 1985.

MÉSZÁROS, István. O desafio e o fardo do tempo histórico: o socialismo no século XXI. Tradução de Ana Cotrim e Vera Cotrim. São Paulo: Boitempo, 2007. p. 85-131.

MONTAÑO, Carlos; DURIGUETO, Maria Lúcia. Estado, Classes e Movimentos Sociais. São Paulo: Cortez, 2010.

PINTO, Celi Regina Jardim. Uma história do feminismo no Brasil. São Paulo: Fundação Perseu Abramo, 2003.

SILVEIRA, Maria Lúcia. ONG caminhos e descaminhos. Folha Feminista, São Paulo, n. 04, jul. 1999. 


\section{temporalis}

TRAGTEMBERG, Maurício. Rosa Luxemburg e a crítica dos fenômenos burocráticos. In: VIGEVANI, Túlio; LOUREIRO, Isabel (Org.). Rosa Luxemburg: a recusa da alienação. São Paulo: Editora da Unesp; Fapesp, 1991. p. 37-47.

WAINRIGHT, Hillary. Ponto de vista: entrevista concebida a Bila Sorj e Mirian Goldenberg. Estudos Feministas, Florianópolis, v. 12, n. 1, p. 115-126, 2000. 